\title{
Nasopharyngeal Cancer pN3 TNM Finding v7
}

National Cancer Institute

\section{Source}

National Cancer Institute. Nasopharyngeal Cancer pN3 TNM Finding v7. NCI Thesaurus. Code C88974.

Nasopharyngeal cancer with metastasis in a lymph node (s) more than $6 \mathrm{~cm}$ in greatest dimension and/or to supraclavicular fossa. Supraclavicular zone or fossa is relevant to the staging of nasopharyngeal carcinoma and is the triangular region orig inally described by Ho. It is defined by three points: (1) the superior margin of the sternal end of the clavicle, (2) the superior marg in of the lateral end of the clavicle, (3) the point where the neck meets the shoulder. This would include caudal portions of levels IV and VB. All cases with lymph nodes (whole or part) in the fossa are considered N3b. (from AJCC 7th Ed.) 